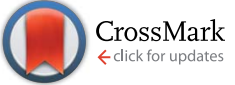

Cite this: RSC Adv., 2017, 7, 12269

Received 13th January 2017

Accepted 6th February 2017

DOI: $10.1039 / \mathrm{c} 7 \mathrm{ra00540 \textrm {g }}$

rsc.li/rsc-advances

\section{Hyperbranched conjugated polymers containing 1,3-butadiene units: metal-free catalyzed synthesis and selective chemosensors for $\mathrm{Fe}^{3+}$ ions $\dagger$}

\begin{abstract}
Chuxin Luo, Yating Liu, Qi Zhang and Xuediao Cai*
Hyperbranched conjugated polymers (P1 and P2) containing 1,3-butadiene repeating units appended with carboxylic ester groups were synthesized in good yield by metal-free catalyzed polymerization of diethyl 4,4' (5-formyl-1,3-phenylene)(2E,2'E)-bis(but-2-enoate) (M1) or dimethyl 4,4'-(5-formyl-1,3-phenylene)(2E,2'E)bis(but-2-enoate) (M2). The corresponding P1 and P2 polymers were structurally characterized by NMR and IR spectroscopy. The polymers are highly soluble in common organic solvents. The UV-vis absorption bands of P2 along with its emission spectrum was red-shifted compared to that of P1, indicating the extension of conjugated length. The hyperbranched conjugated polymers were used as ratiometric fluorescence chemosensors for the detection of the biologically important metal ion $\mathrm{Fe}^{3+}$. The corresponding SternVolmer constants $\left(K_{\mathrm{sv}}\right)$ of $\mathrm{P} 1$ and $\mathrm{P} 2$ are $2.90 \times 10^{4} \mathrm{M}^{-1}$ and $3.83 \times 10^{4} \mathrm{M}^{-1}$, respectively. Detection limits of $6.99 \times 10^{-7} \mathrm{M}$ for P1 and $6.69 \times 10^{-7} \mathrm{M}$ for P2 were achieved. The neutral polymer P1 or P2 was hydrolyzed to obtain water-soluble hyperbranched conjugated polymer P3. The ability of P3 to detect different Fe ${ }^{3+}$ ions in aqueous solution was investigated. The results demonstrate that these polymers can serve as sensitive and selective sensors for $\mathrm{Fe}^{3+}$ ions in organic and aqueous solutions.
\end{abstract}

\section{Introduction}

Hyperbranched conjugated polymers have attracted much attention because of their unique properties, such as good solubility, low viscosity, tunable electrical properties and processability, and also because of their potential applications in organic electronics and optoelectronics, including organic electroluminescence, ${ }^{1-5}$ ion detection, ${ }^{6-8}$ explosive detection, ${ }^{9-14}$ disease diagnosis, ${ }^{15}$ and biological identification. ${ }^{16,17}$ Various transitionmetal-catalyzed polymerization methods have been used for the synthesis of hyperbranched conjugated polymers, such as Suzuki coupling polymerization, ${ }^{18-20}$ click polymerization, ${ }^{21,22}$ and Sonogashira coupling polymerization. ${ }^{23,24}$ These well-established polymerization routes have played an indispensable role in the synthesis of hyperbranched conjugated polymers. However, these methods have drawbacks, such as harsh reaction conditions, tedious synthetic steps, the use of environmentally harmful transition-metal catalysts and solvents. In addition, the trace residues of transition-metal catalysts in polymeric products can seriously affect the efficiency and the life of the resulting devices. ${ }^{25}$

Key Laboratory of Macromolecular Science of Shaanxi Province, School of Chemistry and Chemical Engineering, Shaanxi Normal University, Xi'an 710119, P. R. China. E-mail:xdcai@snnu.edu.cn

$\dagger$ Electronic supplementary information (ESI) available. See DOI: $10.1039 / \mathrm{c} 7 \mathrm{ra00540g}$
Recently, various linear conjugated polymers were synthesized with transition-metal-free catalysed methods. ${ }^{26-35}$ However, these methods, including Wittig reaction, ${ }^{\mathbf{4}, 36}$ Knoevenagel condensation reaction, ${ }^{11}$ arylimino-deoxy-trisubstituted reaction, ${ }^{37}$ and acid-promoted cyclotrimerization reactions, ${ }^{38}$ were rarely explored to prepare hyperbranched conjugated polymers. In addition, these transition-metal-free catalyzed methods also require harsh reaction conditions and complex synthetic steps. Therefore, in order to expand the application of hyperbranched conjugated polymers, it is desirable to develop efficient polymerization method and new structure under mild reaction conditions by using transition-metal-free catalyst.

In our previous work, ${ }^{39}$ we have established an efficient transition-metal-free catalyzed polymerization method. Reactions of $\alpha, \beta$-unsaturated compounds containing $\gamma-\mathrm{H}$ with aldehydes in ethanol in the presence of 1,8-diazabicyclo[5.4.0] undecene-7-ene (DBU) as the basic catalyst gave a series of linear $\pi$-conjugated polymers (Scheme 1 ), which have alternating arylene and 1,3-butadiene units in the main chain. This method has many advantages, including fewer reaction steps, mild reaction conditions, environmentally friendly solvents (i.e., in ethanol even without purity and protection from oxygen), and no toxic metal byproducts. On the basis of these results, herein we report the synthesis of new hyperbranched conjugated polymers containing carboxylic ester groups appended to repeating 1,3-butadiene units and their uses as sensitive and selective sensors for $\mathrm{Fe}^{3+}$ ions in organic and aqueous solutions. Iron is the second most abundant metal 


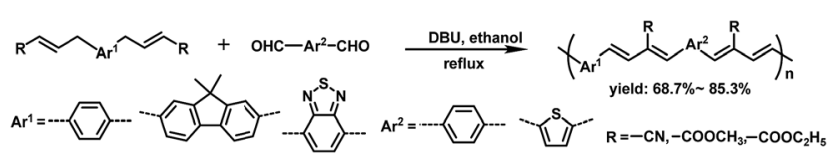

Scheme 1 Synthesis of $\pi$-conjugated polymers containing 1,3-butadiene units in the main chain.

element in nature, and plays very important roles in the whole ecosystem..$^{40}$ Recently, fluorescence sensors based on conjugated polymers for the detection of $\mathrm{Fe}^{3+}$ have received much attention owing to their signal amplification properties..$^{41-48}$

This special macromolecular structure shows several advantages in $\mathrm{Fe}^{3+}$ detection. First, the carboxylic ester group has been reported to act as chelating group for metal ions, especially for $\mathrm{Fe}^{3+}$ ions. Therefore, neutral polymers P1 and P2 are expected to coordinate with $\mathrm{Fe}^{3+}$ in organic solutions, and the strong association interaction between carboxylic ester groups and $\mathrm{Fe}^{3+}$ ions will cause the fluorescence quenching. ${ }^{49}$ Second, the carboxylic ester group could be hydrolyzed to obtain water-soluble hyperbranched conjugated polymers. We expected that our synthesized hyperbranched conjugated polymers could be used in the field of selective detection of $\mathrm{Fe}^{3+}$ from environmental and biological samples.

\section{Experimental}

\section{Materials and instruments}

Chemical reagents and different metal salts were purchased from Energy chemical, Meryer or Aladdin and used as received. THF and 1,4-dioxane were distilled from sodium benzophenone ketyl under dry nitrogen immediately prior to the use. ${ }^{1} \mathrm{H}$ and ${ }^{13} \mathrm{C}$ NMR spectra were recorded on a Brüker $600 \mathrm{MHz}$ spectrophotometer in $\mathrm{CDCl}_{3}$ using tetramethylsilane (TMS, $\delta=0$ ) as an internal reference. IR spectra were taken on a FT-IR Brüker Tensor 27 spectrometer at a nominal resolution of $2 \mathrm{~cm}^{-1}$ using $\mathrm{KBr}$ pellet. UV-vis spectra were collected on Hitachi U-3900 spectrophotometer (Tokyo, Japan). Photoluminescence (PL) spectra were recorded on a Hitachi F-7000 spectrofluorometer (Tokyo, Japan). Thermogravimetric analysis (TGA) measurements were carried out under dry nitrogen on Q1000DSC + LNCS + FACSQ600SDT instruments at $20^{\circ} \mathrm{C} \mathrm{min}{ }^{-1}$. The average molecular weight and polydispersity index (PDI) of the polymers were determined using Viscotek gel permeation chromatography (GPC) analysis with THF as the eluent and polystyrene as the standard. Cyclic voltammetry $(\mathrm{CV})$ was conducted on an electrochemistry workstation (CHI 660A, Chenhua Shanghai) with the polymer film on Pt plate as the working electrode, Pt slice as the counter electrode, and saturated calomel electrode (SCE) as a reference electrode in a $0.1 \mathrm{M}$ tetra- $n$-butylammonium hexafluorophosphate acetonitrile solution at a scan rate of $50 \mathrm{mV} \mathrm{s}^{-1}$. The $\mathrm{pH}$ value was measured by using of a MRFS: TOSHNIWAL $\mathrm{pH}$ meter.

\section{Monomer synthesis}

3,5-Bis(4,4,5,5-tetramethyl-1,3,2-dioxaborolan-2-yl)benzaldehyde (1). Compound 1 was synthesized according to published procedures with a yield of $71 \% .{ }^{50}{ }^{1} \mathrm{H}$ NMR (400 $\mathrm{MHz}, \mathrm{CDCl}_{3}$ ) $\delta(\mathrm{ppm}): 10.06(\mathrm{~s}, 1 \mathrm{H}), 8.49(\mathrm{~s}, 1 \mathrm{H}), 8.41(\mathrm{~s}, 2 \mathrm{H}), 1.36(\mathrm{~s}, 24 \mathrm{H})$. Elemental analysis for $\mathbf{1}\left(\mathrm{C}_{19} \mathrm{H}_{28} \mathrm{~B}_{2} \mathrm{O}_{5}\right)$ : $\mathrm{C}, 63.74 ; \mathrm{H}, 7.88 ; \mathrm{B}, 6.04 ; \mathrm{O}$, 22.34. Found: C, 63.68; H, 7.84; B, 6.12; O, 22.39.

Diethyl 4,4'-(5-formyl-1,3-phenylene)(2E,2'E)-bis(but-2enoate) (M1). Compound 1 ( $1 \mathrm{~g}, 2.79 \mathrm{mmol})$, ethyl $(E)-4$ bromobut-2-enoate $(1.6 \mathrm{~g}, 8.37 \mathrm{mmol})$ and $\mathrm{KF}(1.62 \mathrm{~g}, 27.9$ $\mathrm{mmol}$ ) were dissolved in anhydrous 1,4-dioxane $(30.00 \mathrm{~mL})$. The solution was bubbled under nitrogen at room temperature for $10 \mathrm{~min}$, and then, $\mathrm{Pd}(\mathrm{OAc})_{2}(14.7 \mathrm{mg}, 0.15 \mathrm{mmol})$ was added. The reaction mixture was stirred for 72 hours at room temperature. The reaction solution was then washed with saturated $\mathrm{NaCl}$ water and extracted with $\mathrm{Et}_{2} \mathrm{O}(100 \mathrm{~mL} \times 3)$. The combined organic layer was dried with magnesium sulfate, and the solvent was removed by rotary evaporation. The crude product M1 was purified on silica gel chromatography using petroleum ether/ethyl acetate $(5 / 1, \mathrm{v} / \mathrm{v})$ as the eluent to afford a light yellow oily liquid $(1.1 \mathrm{~g}, 60 \%) .{ }^{1} \mathrm{H}$ NMR $\left(400 \mathrm{MHz}, \mathrm{CDCl}_{3}\right)$ $\delta(\mathrm{ppm}): 9.99(\mathrm{~s}, 1 \mathrm{H}), 7.59(\mathrm{~s}, 1 \mathrm{H}), 7.27(\mathrm{~s}, 1 \mathrm{H}), 7.10-7.01(\mathrm{~m}, 1 \mathrm{H})$, 5.86-5.79 (m, $1 \mathrm{H}), 4.19(\mathrm{~d}, J=6.8 \mathrm{~Hz}, 2 \mathrm{H}), 3.59(\mathrm{~d}, J=6.0 \mathrm{~Hz}$, $2 \mathrm{H}), 1.29$ (d, $J=6.8 \mathrm{~Hz}, 3 \mathrm{H}) \cdot{ }^{13} \mathrm{C}$ NMR $\left(100 \mathrm{MHz}, \mathrm{CDCl}_{3}\right)$ $\delta(\mathrm{ppm}): 191.8,166.1,145.7,139.3,137.2,135.2,128.3,123.1$, 77.3, 77.0, 76.6, 60.3, 37.8, 14.1. Elemental analysis for M1 $\left(\mathrm{C}_{19} \mathrm{H}_{22} \mathrm{O}_{3}\right)$ : C, $76.48 ; \mathrm{H}, 7.43 ; \mathrm{O}, 16.09$. Found: $\mathrm{C}, 76.39 ; \mathrm{H}, 7.35$; $\mathrm{O}, 16.13$.

Dimethyl $\quad 4,4^{\prime}$-(5-formyl-1,3-phenylene)(2E,2'E)-bis(but-2enoate) (M2). The same procedure for M1 was applied for the synthesis of M2, using methyl (E)-4-bromonut-2-enoate instead of ethyl (E)-4-bromonut-2-enoate. The crude product M2 was purified on silica gel chromatography using petroleum ether/ ethyl acetate $(4 / 1, \mathrm{v} / \mathrm{v})$ as the eluent to afford a light yellow oily liquid $(1.16 \mathrm{~g}, 63 \%) .{ }^{1} \mathrm{H}$ NMR $\left(400 \mathrm{MHz}, \mathrm{CDCl}_{3}\right) \delta(\mathrm{ppm}): 9.98$ (s, $1 \mathrm{H}), 7.58(\mathrm{~s}, 2 \mathrm{H}), 7.26(\mathrm{~s}, 1 \mathrm{H}), 7.12-7.05(\mathrm{~m}, 2 \mathrm{H}), 5.85(\mathrm{~d}, J=$ $15.5 \mathrm{~Hz}, 2 \mathrm{H}), 3.73(\mathrm{~s}, 6 \mathrm{H}), 3.59(\mathrm{~d}, J=6.4 \mathrm{~Hz}, 4 \mathrm{H}) .{ }^{13} \mathrm{C}$ NMR $(100$ $\left.\mathrm{MHz}, \mathrm{CDCl}_{3}\right) \delta(\mathrm{ppm}): 191.8,166.5,146.0,139.3,137.2,135.1$, 128.3, 122.7, 77.2, 77.0, 76.7, 51.5, 37.8. Elemental analysis for $\mathrm{M} 2\left(\mathrm{C}_{17} \mathrm{H}_{18} \mathrm{O}_{3}\right): \mathrm{C}, 75.53 ; \mathrm{H}, 6.71 ; \mathrm{O}, 17.76$. Found: $\mathrm{C}, 75.45 ; \mathrm{H}$, $6.67 ; \mathrm{O}, 17.82$.

\section{General polymerization}

To a flask charged with monomer in ethanol solution, DBU was added. The reaction mixture was stirred under refluxed for $72 \mathrm{~h}$. The reaction mixture was then heated at high temperature (110 $\left.{ }^{\circ} \mathrm{C}\right)$ for $8 \mathrm{~h}$. The solvent was removed under reduced pressure, and the residue was extracted with $\mathrm{CH}_{2} \mathrm{Cl}_{2}$ and washed with $\mathrm{HCl}$ solution $(2 \mathrm{M}, 100 \mathrm{~mL} \times 3)$ and water. The solvent was removed under reduced pressure.

Synthesis of polymer P1. M1 $\left(0.3 \mathrm{~g}, 9.08 \times 10^{-4} \mathrm{~mol}\right)$ and DBU $\left(62.16 \mathrm{mg}, 4.09 \times 10^{-4} \mathrm{~mol}\right)$ were used. P1 was obtained as yellow solid (yield: $79 \%) .{ }^{1} \mathrm{H}$ NMR $\left(400 \mathrm{MHz}, \mathrm{CDCl}_{3}\right) \delta(\mathrm{ppm})$ 7.82-7.27 (8H, ArH, $\mathrm{C}=\mathrm{CH}), 6.63-6.62(\mathrm{~d}, J=5.6 \mathrm{~Hz}, 2 \mathrm{H}, \mathrm{CH}=$ $\mathrm{CH}), 6.52-6.50(\mathrm{~d}, J=7.2 \mathrm{~Hz}, 2 \mathrm{H}, \mathrm{CH}=\mathrm{CH}), 4.12-4.08(\mathrm{~m}, 4 \mathrm{H}$, $\mathrm{CH}_{2}$ ), 1.23-1.19 (t, 6H, $\mathrm{CH}_{3}$ ). IR ( $\mathrm{KBr}$ pellet, $\mathrm{cm}^{-1}$ ): 3030, 2914, 1740, 1600, 1450, 1350.

Synthesis of polymer P2. M2 $\left(0.3 \mathrm{~g}, 9.92 \times 10^{-4} \mathrm{~mol}\right)$ and DBU $\left(62.16 \mathrm{mg}, 4.09 \times 10^{-4} \mathrm{~mol}\right)$ were used. P2 was obtained as 
yellow solid (yield: $80 \%) .{ }^{1} \mathrm{H}$ NMR $\left(400 \mathrm{MHz}, \mathrm{CDCl}_{3}\right) \delta(\mathrm{ppm})$ 7.62-7.52 (9H, ArH, C=CH), 6.61-6.59 (d, $J=9.2 \mathrm{~Hz}, 2 \mathrm{H}, \mathrm{CH}=$ $\mathrm{CH}$ ), 6.50-6.47 (d, $J=12.8 \mathrm{~Hz}, 2 \mathrm{H}, \mathrm{CH}=\mathrm{CH}), 4.09\left(\mathrm{~s}, 6 \mathrm{H}, \mathrm{CH}_{3}\right)$. IR (KBr pellet, $\mathrm{cm}^{-1}$ ): 3004, 2908, 1745, 1650, 1480, 1380.

Hydrolysis of P1 or P2 to form P3. Neutral carboxylic-estercontaining polymer ( $\mathrm{P} 1$ or $\mathrm{P} 2$ ) was added to a solution of sodium hydroxide in methanol; the mixture was refluxed for 12 h. $^{6}$ After cooling to room temperature, the mixture was neutralization with dilute hydrochloric acid, the solvent was removed by rotary evaporation and the obtained mixture was dialyzed (MW cutoff, $4 \mathrm{kDa}$ ) against water for 3 days to remove small molecules. FT-IR (KBr, $\mathrm{cm}^{-1}$ ): 3450, 1800, 1650, 1400, 700.

\section{Results and discussion}

\section{Synthesis and structure characterization}

The polymer structures and synthetic routes are shown in Scheme 2. Compound $\mathbf{1}$ was synthesized according to the published procedures. $^{50}$ 3,5-Bis $(4,4,5,5$-tetramethyl-1,3,2dioxaborolan-2-yl) benzaldehyde (1), diethyl 4,4'-(5-formyl-1,3phenylene)(2E,2'E)-bis(but-2-enoate) (M1) and dimethyl 4,4'-(5formyl-1,3-phenylene)(2E,2'E)-bis(but-2-enoate) (M2) were prepared by Pd-catalyzed Suzuki cross-coupling reaction under argon atmosphere. In our previous work, we have established a transition-metal-free polymerization method and successfully synthesized a series of linear conjugated polymers. ${ }^{39}$ In this work, the hyperbranched conjugated polymers P1 and P2 were synthesized by the simple $\mathrm{AB}_{2}$ protocol based on our reported polymerization method. The polycondensation was carried out in the same way by refluxing in ethanol for $72 \mathrm{~h}$ with 1,8 diazabicyclo[5.4.0]undec-7-ene (DBU) as the catalyst. The yield of $\mathrm{P} 1$ and $\mathrm{P} 2$ were $79 \%$ and $80 \%$, respectively. This result indicates that the molecular weight is very less affected by the side group. It is worth noting that the carboxylic esterfunctional group can be readily obtained without special reaction for the monomer during polymerization. All the polymers displayed excellent solubility in common organic solvents such as chloroform, tetrahydrofuran, dichloromethane and chlorobenzene. The water-soluble polymer P3 was obtained by the hydrolysis of P1 or P2 in a solution of sodium hydroxide in methanol with a yield of $80 \%$ (Scheme 3 ). Table 1 summarized

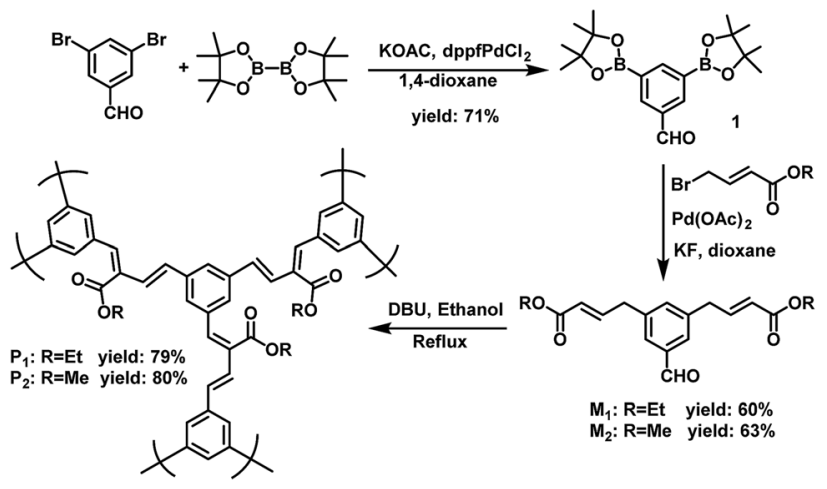

Scheme 2 Synthetic routes of monomers and polymers.

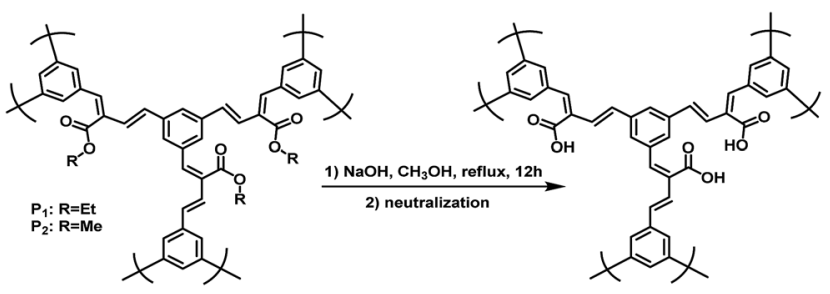

Scheme 3 Synthetic routes of P3.

the polymerization results and thermal properties of the polymers. The number-average molecular weight $\left(M_{\mathrm{n}}\right)$ of P1 and P2 are 6141 and 6026 with polydispersity index (PDI) of 2.575 and 2.465 , respectively. It can be seen that in general, the polymerization afforded conjugated polymers with relatively high molecular weight.

All the monomers were carefully purified and characterized by ${ }^{1} \mathrm{H}$ and ${ }^{13} \mathrm{C}$ NMR (see Experimental section and ESI $\uparrow$ for details). The structures of polymer $\mathrm{P} 1$ and $\mathrm{P} 2$ were verified by ${ }^{1} \mathrm{H}$ NMR and FT-IR. In the ${ }^{1} \mathrm{H}$ NMR spectrum of P1, the peaks attributable to the aromatic protons were observed at 7.82$7.27 \mathrm{ppm}$. Another set of olefinic protons were observed at 6.636.62 and $6.52-6.50 \mathrm{ppm}$. The proton signals of ester methylene and methyl for P1 appear at 4.12-4.08 and 1.23-1.19 ppm, respectively (Fig. S6 $\dagger$ ). In the ${ }^{1} \mathrm{H}$ NMR spectrum of $\mathrm{P} 2$, the peak at $4.09 \mathrm{ppm}$ is assigned to the signal from $-\mathrm{COOCH}_{3}$ of $\mathrm{P} 2$ (Fig. S7 $\dagger$ ). Examples of the IR spectra of P1 and P2 are given in Fig. S9. $\uparrow$ P1 and P2 shows absorption bands at 3030 and 3004 $\mathrm{cm}^{-1}$ due to their $\mathrm{CH}=\mathrm{CH}$ stretching vibrations. The strong peaks at $1740 \mathrm{~cm}^{-1}$ for $\mathrm{P} 1$ and $1745 \mathrm{~cm}^{-1}$ for $\mathrm{P} 2$ are associated with their $\mathrm{C}=\mathrm{O}$ groups. As for $\mathrm{P} 3$, we see a broad band of strong absorption peaks at $3450 \mathrm{~cm}^{-1}$ due to its $\mathrm{OH}$ stretching vibrations of $\mathrm{COOH}$ groups. IR spectrum indicated successful synthesis of the target polymers P1, P2 and P3. Because of the poor resolution of related resonances in the ${ }^{1} \mathrm{H}$ NMR spectra of P1 and P2, the important parameter of degree of branching is hardly assessed.

\section{Thermal properties}

The thermal properties of the target polymers were obtained by thermogravimetric analysis (TGA) under a nitrogen atmosphere at a heating rate of $20{ }^{\circ} \mathrm{C} \mathrm{min}{ }^{-1}$. The TGA diagram of $\mathrm{P} 1$ (shown in Fig. S10 $\dagger$ ) showed a mass loss of $5 \%$ starting at $240{ }^{\circ} \mathrm{C}$ as the threshold of the thermal decomposition, and a loss of about $50 \%$ at $500{ }^{\circ} \mathrm{C}$. On the other hand, the TGA trace of $\mathrm{P} 2$ showed

Table 1 Molecular weights and thermal properties of polymers

\begin{tabular}{llllll}
\hline Polymer & Yield (\%) & $M_{\mathrm{n}}{ }^{a}$ & $M_{\mathrm{w}}{ }^{a}$ & $\mathrm{PDI}^{a}$ & $T_{\mathrm{d}}{ }^{b}\left[{ }^{\circ} \mathrm{C}\right]$ \\
\hline P1 & $72 \%$ & 6141 & 15812 & 2.575 & 240 \\
P2 & $75 \%$ & 6026 & 14854 & 2.465 & 200
\end{tabular}

${ }^{a}$ Determined by GPC at using THF as an eluent against polystyrene standards. ${ }^{b} 5 \%$ weight loss temperature measured by TGA under a nitrogen atmosphere. 
that polymer decomposition started at $200{ }^{\circ} \mathrm{C}$ and the weight loss was about $55 \%$ at $600{ }^{\circ} \mathrm{C}$.

\section{Photophysical properties}

Fig. 1a and b depict the UV-vis spectra of polymer P1 and P2, respectively, measured in different organic solvents, including $\mathrm{CH}_{2} \mathrm{Cl}_{2}$, DMSO, $\mathrm{CH}_{3} \mathrm{CH}_{2} \mathrm{OH}$, THF, and in solid-state films. P1 and $\mathrm{P} 2$ exhibited no significant absorption peaks in most tested organic solvents, while they showed significant absorption peaks at 325 and $330 \mathrm{~nm}$ in THF, respectively (Fig. 1). The different absorption features of $\mathrm{P} 1$ and $\mathrm{P} 2$ in these solvents are due to the different polarity of solvents. It is reported that molecular aggregation in solution exhibited distinct change in the absorption band and can possibly be influenced by the polarity of solvents. ${ }^{16}$ The polymer P1 in THF solution showed an absorption maximum at $325 \mathrm{~nm}$ attributable to phenyl moiety. The solid film of P1 also showed a similar absorption behaviour with an absorption maximum at $327 \mathrm{~nm}$. This result indicates the low aggregation degree of P1 hyperbranched chains in the thin film state. On the other hand, polymer P2 in THF solution showed an absorption peak at $330 \mathrm{~nm}$ corresponding to phenyl moiety. The absorption peaks were redshifted compared to those of P1, suggesting an extension of the conjugated length. It is likely that the substituent has a steric influence on the electronic structure, possibly due to the fact that bulky groups can interrupt the linear $\pi$-system, leading to the reduction in the $\pi$-conjugated length. The solid film of P2 showed a similar absorption behavior with an absorption maximum at $350 \mathrm{~nm}$. The absorption peaks are red-shifted compared to their solution absorption spectra, which was mainly attributed to the enhanced intermolecular interactions between neighboring molecules in the film state.

The photoluminescent (PLs) spectra of the hyperbranched conjugated polymers in solution excited at the absorption maxima are shown in Fig. 2a and b. As shown in Fig. 2a and b, P1 and P2 exhibited low fluorescence intensity in most organic solvents, while they showed relatively high fluorescence intensity in THF: P1 displayed an emission peak at $410 \mathrm{~nm}(450 \mathrm{~nm}$ in the solid state); P2 showed a peak maximum at $420 \mathrm{~nm}$ (460 $\mathrm{nm}$ in the solid state). The emission peaks of both P1 and P2 in the solid state are broaden and red-shifted compared with those in THF solution. This result suggests the formation of aggregates in the solid state. The fluorescence quantum yields $\left(\Phi_{\mathrm{F}}\right)$ of the polymers in THF were measured in comparison with
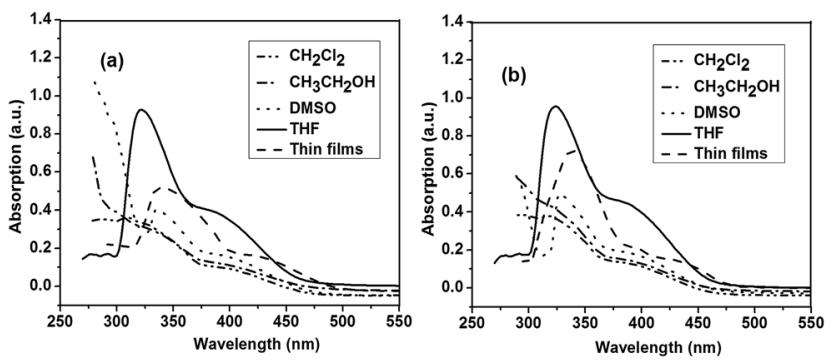

Fig. 1 UV-vis spectra of (a) P1 and (b) P2.
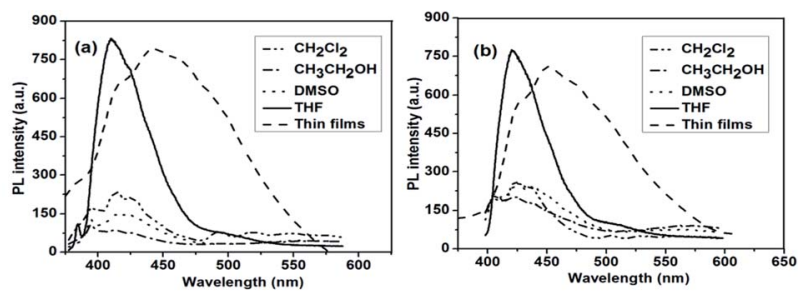

(c)

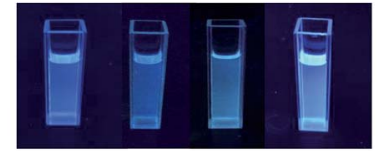

$\mathrm{CH}_{2} \mathrm{Cl}_{2} \quad \mathrm{CH}_{3} \mathrm{CH}_{2} \mathrm{OH}$ DMSO THF

(d)

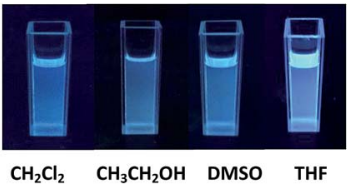

Fig. 2 Fluorescence spectra of (a) P1 and (b) P2. Emission images observed for (c) P1 and (d) P2 measured in different solutions.

quinine sulfate as a standard (in $0.1 \mathrm{M} \mathrm{H}_{2} \mathrm{SO}_{4}$ solution, $\Phi_{\mathrm{F}}=$ 0.55). ${ }^{51}$ The results are $32 \%$ for $\mathrm{P} 1$ and $34 \%$ for $\mathrm{P} 2$. The relatively low quantum yields of P1 and P2 might be caused by imperfect structures presented in the hyperbranched polymers with higher contents of branch units and carboxylic ester groups attached to the main chain, which reduced the conjugated length.

\section{Electrochemical properties}

The electrochemical behaviors of polymers P1 and P2 were investigated by cyclic voltammetry (CV) as shown in Fig. 3 (the results are summarized in Table 2). CV was performed in acetonitrile $\left(0.1 \mathrm{M} \mathrm{Bu}_{4} \mathrm{NF}_{6}\right)$ at a scan rate of $50 \mathrm{mV} \mathrm{s}^{-1}$ at room temperature using an SCE as the reference electrode (all potentials reported are versus SCE). A platinum electrode coated with a thin polymer film was used as the working electrode. The onset potentials for oxidation $\left(E_{\text {ox }}\right)$ are observed to be $0.55 \mathrm{~V}$ and $0.54 \mathrm{~V}$ for $\mathrm{P} 1$ and $\mathrm{P} 2$, respectively, and the reduction $\left(E_{\text {red }}\right)$ of P1 and $\mathrm{P} 2$ were found to be $-0.75 \mathrm{~V}$ and $-0.74 \mathrm{~V}$, respectively. With the formula $E_{\mathrm{HOMO}}=-e\left(E_{\mathrm{Ox}}+4.29\right) \mathrm{eV}$ and $E_{\mathrm{LUMO}}=-e\left(E_{\mathrm{red}}+\right.$ 4.29) $\mathrm{eV}$, we estimated the highest occupied molecular orbital (HOMO) and the lowest unoccupied molecular orbital (LUMO) energy levels of the polymer P1 and P2 to be $-4.80 \mathrm{eV},-4.79 \mathrm{eV}$ and $-3.54 \mathrm{eV},-3.55 \mathrm{eV}$, respectively. There are no obvious differences in the HOMO and LUMO levels between polymers

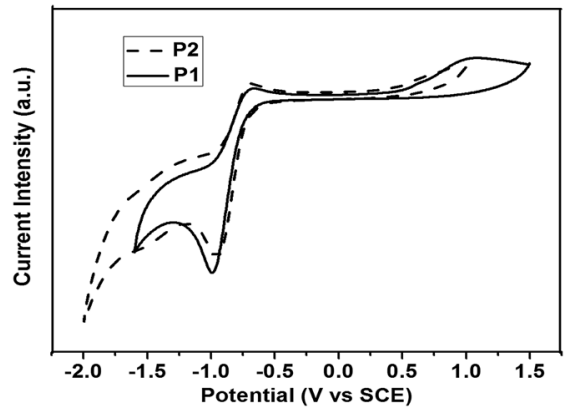

Fig. 3 Cyclic voltammograms of the polymer in $0.1 \mathrm{M} \mathrm{Bu}_{4} \mathrm{NPF}_{6}$ acetonitrile solution. 
Table 2 Optical and electrical properties of the polymers

\begin{tabular}{llllll}
\hline Polymer & Abs. (nm) & $\mathrm{PL}_{(\mathrm{nm})}{ }^{a}$ & $\mathrm{HOMO}^{b}(\mathrm{eV})$ & $\mathrm{LUMO}^{b}(\mathrm{eV})$ & $E_{\mathrm{g}}{ }^{c}(\mathrm{eV})$ \\
\hline P1 & 325,380 & 410 & -4.80 & -3.54 & 1.26 \\
P2 & 330,385 & 420 & -4.79 & -3.55 & 1.21
\end{tabular}

${ }^{a}$ THF was used as an the synthesis solvent. ${ }^{b} E(\mathrm{HOMO})=-e\left(E_{\mathrm{ox}}+\right.$ 4.29) $\mathrm{eV}, E(\mathrm{LUMO})=-e\left(E_{\text {red }}+4.29\right) \mathrm{eV}$, observed in the cyclic voltammetric analyses. ${ }^{c} E_{\mathrm{g}}=E(\mathrm{LOMO})-E(\mathrm{HOMO})(\mathrm{eV})$.

P1 and P2 due to the same main chain structures and the same end groups.

\section{Ion sensing properties}

Due to the same main chain of P1 and P2, we chose polymer P1 as a model to investigate its ion sensing property. The results of P2 about ion sensing property were shown in ESI. $\dagger$ The ion sensing properties of polymer P1 was investigated for various metal ions. Variations in the UV-vis absorption and fluorescence spectra of $\mathrm{P} 1$ were caused by various competitive metal ions, including $\mathrm{Mg}^{2+}, \mathrm{Al}^{3+}, \mathrm{K}^{+}, \mathrm{Fe}^{3+}, \mathrm{Cu}^{2+}, \mathrm{Ba}^{2+}, \mathrm{Ni}^{2+}, \mathrm{Zn}^{2+}, \mathrm{Mn}^{2+}$, $\mathrm{Pb}^{2+}, \mathrm{Ag}^{+}, \mathrm{Hg}^{2+}, \mathrm{Ca}^{2+}, \mathrm{Li}^{+}$and $\mathrm{Cd}^{2+}$. The measured concentration of P1 in THF was $1.0 \times 10^{-5} \mathrm{M}$. The influence of different metal ions $\left([\right.$ metal ion $\left.]=1.0 \times 10^{-4} \mathrm{M}\right)$ on the UV-vis absorption spectra and fluorescence intensity of P1 are shown in Fig. 4a and b. From the UV-vis absorption spectra (Fig. 4a), we can see that $\mathrm{P} 1$ showed a significant absorption band centered at about $325 \mathrm{~nm}$ upon addition of $\mathrm{Fe}^{3+}$ ions, whereas weaker absorption bands were observed with other ions. Emission quench was observed for $\mathrm{P} 1$ upon addition of $\mathrm{Fe}^{3+}$ and $\mathrm{Cu}^{2+}$, and the quench with $\mathrm{Fe}^{3+}$ ions is much more significant compared to that with $\mathrm{Cu}^{2+}$. No fluorescence reduce was observed upon treatment with other metal ions. This result indicates the good selectivity of P1 toward the sensing of $\mathrm{Fe}^{3+}$. According to Swager's group reported, if the absorption peak of UV-vis spectra was red-shifted, the mechanism of quenching is consistent with the static quenching by a charge transfer complex. ${ }^{49}$ For P1 the addition of $1.0 \times 10^{-4} \mathrm{M} \mathrm{Fe}^{3+}$ shifts the absorption onset from $325 \mathrm{~nm}$ to $334 \mathrm{~nm}$ (Fig. 4a). For P2 shows the similar phenomenon from $330 \mathrm{~nm}$ to $340 \mathrm{~nm}$ (Fig. S12 $\dagger$ ). Therefore, these results indicate that the fluorescence quenching induced by $\mathrm{Fe}^{3+}$ occurs mainly via static quenching mechanism owing to the strong association interaction between the $\mathrm{Fe}^{3+}$ ions and the receptors,
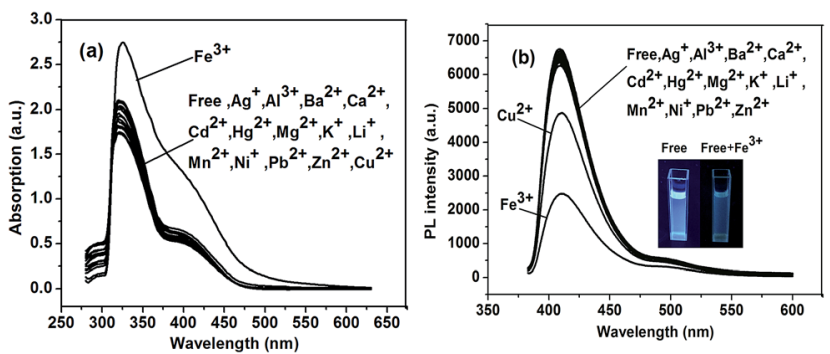

Fig. 4 (a) UV-vis absorption spectra of P1; (b) fluorescence spectra and images of $\mathrm{P} 1$. carboxylic ester groups (the proposal mechanism was shown in Fig. S11†). ${ }^{52}$

In order to quantitatively measure the effect of metal cations on fluorescence intensity, we calculated the relative fluorescence intensity $\left(I / I_{0}\right)$, in which $I_{0}$ is the fluorescence intensity without addition of quencher and $I$ is the fluorescence intensity after the addition of metal cations. The $I / I_{0}$ values of $\mathrm{P} 1$ and $\mathrm{P} 2$ for $\mathrm{Mg}^{2+}, \mathrm{Al}^{3+}, \mathrm{K}^{+}, \mathrm{Ba}^{2+}, \mathrm{Ni}^{2+}, \mathrm{Zn}^{2+}, \mathrm{Mn}^{2+}, \mathrm{Pb}^{2+}, \mathrm{Ag}^{+}, \mathrm{Hg}^{2+}, \mathrm{Ca}^{2+}$, $\mathrm{Li}^{+}$and $\mathrm{Cd}^{2+}$ are almost 1 . However, this value of $\mathrm{P} 1$ is 0.72 and 0.36 for $\mathrm{Cu}^{2+}$ and $\mathrm{Fe}^{3+}$, respectively; this value of $\mathrm{P} 2$ is 0.72 and 0.41 for $\mathrm{Cu}^{2+}$ and $\mathrm{Fe}^{3+}$, respectively. Conspicuously, the highest fluorescence quenching effect of both P1 and P2 was observed in the presence of $\mathrm{Fe}^{3+}$ ions.

Fig. 5 shows the fluorescence change of P1 upon titration with $\mathrm{Fe}^{3+}$ ion $\left(\left[\mathrm{Fe}^{3+}\right]=0\right.$ to $\left.120 \times 10^{-6} \mathrm{M}\right)$. With addition of $\mathrm{Fe}^{3+}$ ions, the fluorescence intensity of $\mathrm{P} 1$ at $425 \mathrm{~nm}$ continuously reduced. The corresponding Stern-Volmer constants $\left(K_{\mathrm{sv}}\right)$ were calculated from the Stern-Volmer relationships (eqn (1)), ${ }^{53}$ where $[\mathrm{Q}]$ is the concentration of the quencher (i.e., $\mathrm{Fe}^{3+}$ ).

$$
I_{0} / I=1+K_{\mathrm{sv}}[\mathrm{Q}]
$$

At low concentration $\left(0\right.$ to $\left.20 \times 10^{-6} \mathrm{M}\right), I_{0} / I$ increases linearly with the concentration of quencher. The corresponding Stern-Volmer constant $\left(K_{\text {sv }}\right)$ were calculated to be $2.90 \times 10^{4}$ $\mathrm{M}^{-1}$ for P1 and $3.83 \times 10^{4} \mathrm{M}^{-1}$ for P2 (shown in ESI S13 $\dagger$ ). On the basis of these relationships and $3 \times \delta_{\text {blank }} / k$ (where $\delta_{\text {blank }}$ is the standard deviation of the blank solution and $k$ is the slop of the calibration plot), the detection limit was determined by blank standard method and was calculated to be $6.99 \times 10^{-7} \mathrm{M}$ for $\mathrm{P} 1$ and $6.69 \times 10^{-7} \mathrm{M}$ for $\mathrm{P} 2$. These numbers indicated that both $\mathrm{P} 1$ and $\mathrm{P} 2$ were highly sensitive to $\mathrm{Fe}^{3+}$ ions.

It is well known that large side groups attached to the polymer backbone will reduce the inter polymer aggregation. We investigated the fluorescent quenching of P1 and P2 in THF solution upon the addition of $\mathrm{Fe}^{3+}$ ions. The absorption and emission spectra, and the quantum yield of P1 and P2 in THF solution are very similar, which implied the change of side groups did not have much influence on the main chain of the polymer. However, $\mathrm{Fe}^{3+}$-induced quenching is much less efficient for $\mathrm{P} 1\left(K_{\mathrm{Sv}}=2.90 \times 10^{4} \mathrm{M}^{-1}\right)$ than $\mathrm{P} 2\left(K_{\mathrm{sv}}=3.83 \times 10^{4}\right.$ $\mathrm{M}^{-1}$ ), which indicates the bulky side groups indeed stifle interpolymer aggregation and lower the response to metal ions as expected. ${ }^{54}$
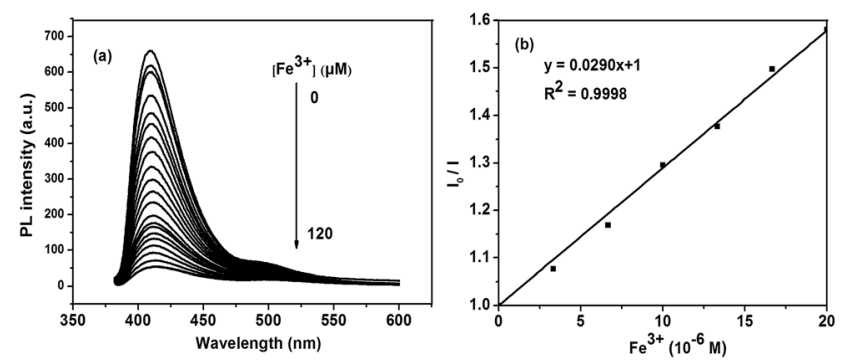

Fig. 5 (a) Fluorescence response of $\mathrm{P} 1$ to $\mathrm{Fe}^{3+}$ in THF solution; (b) the concentration line chart of P1. 


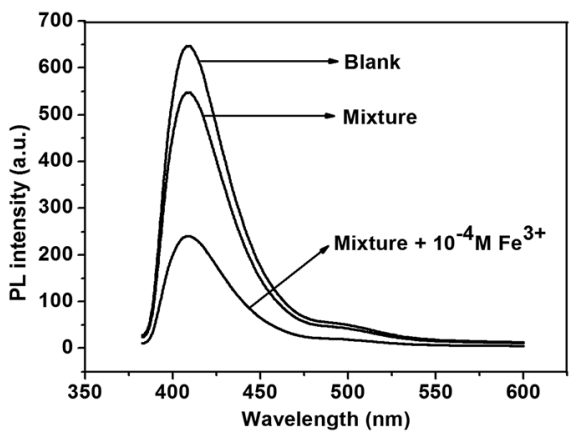

Fig. 6 Fluorescence change of P1 upon titration of metal ion mixtures (concentration of each metal ion was $10^{-4} \mathrm{M}$ ) with or without $\mathrm{Fe}^{3+}$ in THF solution.

It is reported that the interference from other metal ions will influence the fluorescence quenching assay for a specific metal ion when the sensor is used in complex media. The selectivity of polymers for $\mathrm{Fe}^{3+}$ in the presence of excesses various metal ions was investigated (Fig. 6, and $\mathrm{S} 14 \uparrow$ for $\mathrm{P} 2$ ). Upon addition of a mixture of metal ions including $\mathrm{Mg}^{2+}, \mathrm{Al}^{3+}, \mathrm{K}^{+}, \mathrm{Cu}^{2+}, \mathrm{Ba}^{2+}$, $\mathrm{Ni}^{2+}, \mathrm{Zn}^{2+}, \mathrm{Mn}^{2+}, \mathrm{Pb}^{2+}, \mathrm{Ag}^{+}, \mathrm{Hg}^{2+}, \mathrm{Ca}^{2+}, \mathrm{Li}^{+}$and $\mathrm{Cd}^{2+}$ (concentration of each metal ion was $1.0 \times 10^{-4} \mathrm{M}$ ), the fluorescence intensity of P1 has negligible change. However, when $\mathrm{Fe}^{3+}(1.0$ $\times 10^{-4} \mathrm{M}$ ) was added to the mixture solution, the fluorescence intensity could be quenched up to $62 \%$ of P1 and $57 \%$ for P2.

\section{Ion sensing properties of water-soluble polymer P3}

Water-soluble hyperbranched conjugated polymer P3 was obtained by hydrolysis of neutral polymer $\mathrm{P} 1$ or $\mathrm{P} 2$. The structure of P3 was determined by IR (Fig. S9†), showing a strong broad absorption band at $3450 \mathrm{~cm}^{-1}$ attributed to the $\mathrm{OH}$ stretching vibration of $-\mathrm{COOH}$ group in $\mathrm{P} 3$.

Polymer P3 was also examined as a sensor for metal cations. As shown in Fig. 7, dramatic quenching of the emission by $\mathrm{Fe}^{3+}$ was observed, while almost no change could be found in the presence of other cations (a small quenching was observed with $\mathrm{Cu}^{2+}$ ), indicating the good selectivity of $\mathrm{P} 3 \mathrm{for}_{\mathrm{Fe}}{ }^{3+}$ in aqueous solution.

Fig. S15† showed the titration of $\mathrm{P} 3$ with $\mathrm{Fe}^{3+}$ in aqueous solution. The fluorescence intensity at $415 \mathrm{~nm}$ exhibited a good linear relationship with the concentration of $\mathrm{Fe}^{3+}(0-40 \mu \mathrm{M})$.

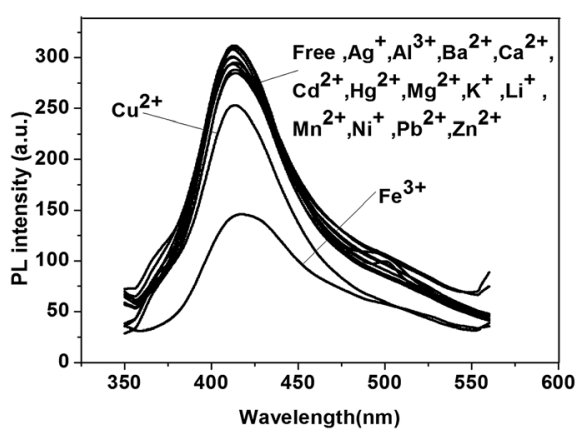

Fig. 7 The fluorescence spectra of P3.

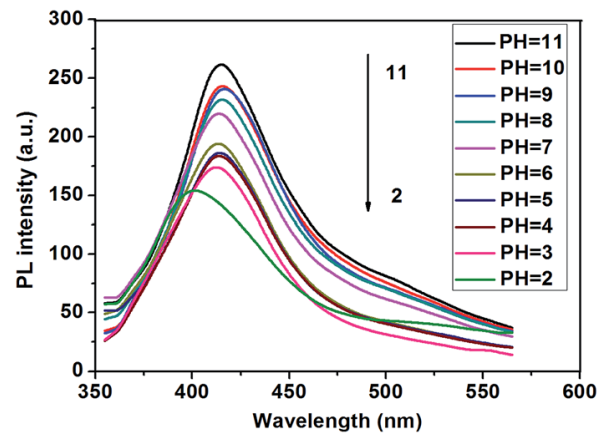

Fig. $8 \mathrm{pH}$-Dependent emission spectra of P3.

The corresponding Stern-Volmer constants $\left(K_{\mathrm{sv}}\right)$ was calculated to be $1.17 \times 10^{4} \mathrm{M}^{-1}$, and the detection limit was determined to be $5.86 \times 10^{-6} \mathrm{M}$. According to the results, water-soluble P3 could be considered as a selective detector of $\mathrm{Fe}^{3+}$ ion in aqueous environment.

In order to investigate the $\mathrm{pH}$ effect on the fluorescent properties of $\mathrm{P} 3$, we measured the fluorescence in $10 \mathrm{mM}$ $\mathrm{NaH}_{2} \mathrm{PO}_{4}-\mathrm{Na}_{2} \mathrm{HPO}_{4}$ buffer solutions with a pH range of 2 to 11 . As show in Fig. 8, at basic level $(\mathrm{pH} \geq 7)$, P3 exhibits similar emission behavior with the emission maximum located approximately at $415 \mathrm{~nm}$, which is nearly identical to its neutral polymer P1 and P2 in THF. This result indicates that the polymer isolates well in basic solutions. As the $\mathrm{pH}$ decreases to 2, a break point is observed where the absorption maximum shifts from 415 to $400 \mathrm{~nm}$. A further decrease in the $\mathrm{pH}$ results in significant reduction of the emission intensity of $\mathrm{P} 3$. This $\mathrm{pH}-$ dependent fluorescence property indicates that P3 may have two different forms under different $\mathrm{pH}$ conditions. ${ }^{6}$ At high $\mathrm{pH}$, the majority of the carboxylic acid groups are deprotonated (the anionic form). The electrostatic repulsions between anionic carboxylate groups surrounding the polymer backbones reduce the unfavorable aggregation of the polymer chains. While at low $\mathrm{pH}$, the carboxylate groups can be partially neutralized, leading to decreased charge density and thus a decrease in the inter chain electrostatic repulsion. On one hand, P3 may aggregate through hydrogen bonding between carboxylic acid groups and aromatic $\pi-\pi$ stacking of hydrophobic backbones. On the other hand, the carboxylic acids make the conjugated main chain twisted and thus decrease the conjugated length. Therefore, at low $\mathrm{pH}$, the emission maxima show blue shift.

\section{Conclusion}

In summary, we have synthesized functional hyperbranched polymers containing carboxylic ester groups attached to 1,3butadiene repeating units. Synthesized polymers P1 and P2 are soluble in common organic solvents and are thermally stable. The neutral hyperbranched conjugated polymers can be hydrolyzed to obtain water-soluble hyperbranched conjugated polymer P3. The fluorescence intensity of these hyperbranched polymers had a good linear response with $\mathrm{Fe}^{3+}$ ions over other ions, indicating their potential uses as ratiometric fluorescence chemosensor for $\mathrm{Fe}^{3+}$ ions in organic and aqueous solutions. 


\section{Acknowledgements}

This work was supported by National Science Basic Research Plan in Shaanxi Province of China (2016JM2019) and the National Key Research Project MOST (2016YFA0202400).

\section{Notes and references}

1 X.-Y. Cao, X.-H. Zhou, H. Zi and J. Pei, Macromolecules, 2004, 37, 8874-8882.

2 Y. Xin, G.-A. Wen, W.-J. Zeng, L. Zhao, X.-R. Zhu, Q.-L. Fan, J.-C. Feng, L.-H. Wang, W. Wei, B. Peng, Y. Cao and W. Huang, Macromolecules, 2005, 38, 6755-6758.

3 J. Sun, J. Yang, C. Zhang, H. Wang, J. Li, S. Su, H. X. Xu, T. Zhang, Y. Wu, W.-Y. Wong and B. Xu, New J. Chem., 2015, 39, 5180-5188.

4 K. R. Prashanth Kumar, M. G. Murali and D. Udayakumar, Des. Monomers Polym., 2014, 17, 7-18.

5 W. Wu, R. Tang, Q. Li and Z. Li, Chem. Soc. Rev., 2015, 44, 3997-4022.

6 B. Bao, X. Zhan and L. Wang, J. Polym. Sci., Part A: Polym. Chem., 2010, 48, 3431-3439.

7 W. Ding, H. Zhang, J. Xu, Y. Wen, J. Zhang, H. Liu, Y. Yao and Z. Zhang, J. Polym. Sci., Part A: Polym. Chem., 2016, 54(23), 3694-3700.

8 H. Li, X. Wu, Y. Xu, H. Tong and L. Wang, Polym. Chem., 2014, 5, 5949-5956.

9 L. Chen, Y. Gao, Y. Fu, D. Zhu, Q. He, H. Cao and J. Cheng, RSC Adv., 2015, 5, 29624-29630.

10 Y. Xu, X. Wu, Y. Chen, H. Hang, H. Tong and L. Wang, Polym. Chem., 2016, 7, 4542-4548.

11 X.-S. Ma, Y.-Z. Cui, Y.-Q. Ding, F.-R. Tao, B. Zheng, R.-H. Yu and W. Huang, Sens. Actuators, B, 2017, 238, 48-57.

12 B. Zheng, Y. Li, F. Tao, Y. Cui and T. Li, Sens. Actuators, B, 2017, 241, 357-363.

13 R. Hu, J. W. Y. Lam, J. Liu, H. H. Y. Sung, I. D. Williams, Z. Yue, K. S. Wong, M. M. F. Yuend and B. Z. Tang, Polym. Chem., 2012, 3, 1481-1489.

14 W. Z. Yuan, R. Hu, J. W. Y. Lam, N. Xie, C. K. W. Jim and B. Z. Tang, Chem.-Eur. J., 2012, 18, 2847-2856.

15 D. Ding, G. Wang, J. Liu, K. Li, K.-Y. Pu, Y. Hu, J. C. Y. Ng, B. Z. Tang and B. Liu, Small, 2012, 8(22), 3523-3530.

16 H. Ejima, H. Matsuno and T. Serizawa, Langmuir, 2010, 26, 17278-17285.

17 D. Wang, T. Zhao, X. Zhu, D. Yan and W. Wang, Chem. Soc. Rev., 2015, 44, 4023-4071.

$18 \mathrm{X} . \mathrm{Wu}, \mathrm{H} . \mathrm{Li}, \mathrm{Y} . \mathrm{Xu}, \mathrm{H}$. Tong and L. Wang, Polym. Chem., 2014, 6, 2305-2311.

19 J. Sun, J. Yang, C. Zhang, H. Wang, J. Li, S. Su, H. Xu, T. Zhang, Y. Wu, W.-Y. Wong and B. Xu, New J. Chem., 2015, 39, 5180-5188.

20 H. T. Nguyen, L.-T. T. Nguyen, T. T. Nguyen, A. T. Luu and T. V. Le, J. Polym. Res., 2014, 21(552), 2-11.

21 D. Li, X. Wang, Y. Jia, A. Wang and Y. Wu, Chin. J. Chem., 2012, 30, 861-868.

22 J. Wang, J. Mei, E. Zhao, Z. Song, A. Qin, J. Z. Sun and B. Z. Tang, Macromolecules, 2012, 45, 7692-7703.
23 C. P. Sen, V. D. Goud, R. G. Shrestha, L. K. Shrestha, K. Ariga and S. Valiyaveettil, Polym. Chem., 2016, 7, 4213-4225.

24 J. Qu, M. Shiotsuki, N. Kobayashi, F. Sanda and T. Masuda, Polymer, 2007, 48, 6481-6490.

25 J. Oriou, F. Ng, G. Hadziioannou, G. Garbay, M. Bousquet, L. Vignau, E. Cloutet and C. Brochon, Polym. Chem., 2014, 5, 7100-7108.

26 M. R. Raj and S. Anandan, RSC Adv., 2013, 3, 14595-14608.

27 S. Chhatre, S. Agarkar, V. Dhas, S. Nagane, V. Thakare, S. Ogale and P. Wadgaonkar, J. Mater. Chem., 2012, 22, 23267-23271.

28 M. Yoon, H. W. Yoon, A. J. Kim, R. S. Ree, Y.-S. Gal, J. W. Lee, J. H. Lee and S.-H. Jin, Mol. Cryst. Liq. Cryst., 2011, 550, 304310.

29 B. J. Laughlin and R. C. Smith, Macromolecules, 2010, 43, 3744-3749.

30 S. Barik, T. Bletzacker and W. G. Skene, Macromolecules, 2012, 45, 1165-1173.

31 S. Barik and W. G. Skene, Polym. Chem., 2011, 2, 1091-1097. 32 S. Dufresne and W. G. Skene, J. Phys. Org. Chem., 2012, 25, 211-221.

33 A. Upadhyay and S. Karpagam, Polym. Bull., 2016, 73, 27412760.

34 M. S. Maji, T. Pfeifer and A. Studer, Chem.-Eur. J., 2010, 16, 5872-5875.

35 M. Bourgeaux and W. G. Skene, Macromolecules, 2007, 40, 1792-1795.

36 Q. He, F. Bai, J. Yang, H. Lin, H. Huang, G. Yu and Y. Li, Thin Solid Films, 2002, 417, 183-187.

37 Y. Sun, Y. Sun, Q. Pan, G. Li, B. Han, D. Zeng, Y. Zhang and H. Cheng, Chem. Commun., 2016, 52, 3000-3002.

38 X.-Y. Cao, W.-B. Zhang, J.-L. Wang, X.-H. Zhou, H. Lu and J. Pei, J. Am. Chem. Soc., 2003, 125, 12430-12431.

39 X. Cai, Y. Liu, T. Lu, R. Yang, C. Luo, Q. Zhang and Y. Chai, Macromol. Rapid Commun., 2016, 37, 2005-2010.

40 J. Y. Cabon, P. Giamarchi and A. L. Bihan, Anal. Chim. Acta, 2010, 664, 114-120.

41 B. Muthuraj, S. Hussain and P. K. Iyer, Polym. Chem., 2013, 4, 5096-5107.

42 G. Saikia and P. K. Iyer, Macromolecules, 2011, 44, 3753-3758. 43 J. Y. Xu, Y. Zhou, G. F. Cheng, S. X. Liu, M. T. Dong and C. B. Huang, Luminescence, 2015, 30, 451-456.

44 C. J. Qin, Y. X. Cheng, L. X. Wang, X. B. Jing and F. S. Wang, Macromolecules, 2008, 41, 7798-7804.

45 P. Li, Y. Zhao, L. Yao, H. Nie and M. Zhang, Sens. Actuators, B, 2014, 191, 332-336.

46 W. C. Ding, J. K. Xu, Y. P. Wen, H. Zhang and J. J. Zhang, J. Photochem. Photobiol., A, 2016, 314, 22-28.

47 X. F. Wu, B. W. Xu, H. Tong and L. X. Wang, Macromolecules, 2010, 43, 8917-8923.

48 H. Zhang, G. Zhang, J. K. Xu, Y. P. Wen, B. Y. Lu, J. Zhang and D. W. Ding, Sens. Actuators, B, 2016, 230, 123-129.

49 Q. Zhou and T. M. Swager, J. Am. Chem. Soc., 1995, 117, 70177018.

50 K. Ono, R. Aizawa, T. Yamano, S. Ito, N. Yasuda, K. Johmoto, H. Uekusa and N. Iwasawa, Chem. Commun., 2014, 50, 13683-13686. 
51 D. Nagaraja, R. M. Melavanki, N. R. Patil, H. S. Geethanjali and R. A. Kusanur, Luminescence, 2015, 30, 495-502.

52 G. Zhou, Y. Cheng, L. Wang, X. Jing and F. Wang, Macromolecules, 2005, 38, 2148-2153.
53 J. R. Lakowicz, Principles of Fluorescence Spectroscopy; Kluwer Academic/Plenum Publishers: New York, 1999.

54 H. Tong, L. Wang, X. Jing and F. Wang, Macromolecules, 2002, 35, 7169-7171. 